\title{
Letters
}

\section{Iron deficiency anaemia}

\section{Gastrointestinal endoscopy should always be used}

EDITOR-As gastroenterologists, we believe that Rebecca Frewin and colleagues' article on iron deficiency anaemia is superficial. ${ }^{1}$ We have regularly assessed and audited the care of some 100 patients a year over 10 years. The finding of cutaneous changes such as angular stomatitis is rare, and koilonychia and oesophageal or pharyngeal webs are almost never seen. Only a small proportion of our patients have symptoms or signs pointing to the cause. In particular, the most rewarding diagnoses, such as coeliac disease and carcinoma of the colon, rarely have other symptoms. It consequently becomes important to investigate both the upper and the lower gastrointestinal tract as a matter of urgency. ${ }^{2}$

When we audited the investigation of iron deficiency anaemia we were unable to find any role for estimation of urea and electrolyte concentrations, liver function tests, or analysis of urine for occult renal blood loss. ${ }^{3}$ As lesions tend to bleed intermittently there is also no established role for estimation of

\section{Advice to authors}

We receive more letters than we can publish:we can currently accept only about one third. We prefer short letters that relate to articles published within the past four weeks. We also publish some "out of the blue"letters, which usually relate to matters of public policy.

When deciding which letters to publish we favour originality, assertions supported by data or by citation, and a clear prose style. Letters should have fewer than 400 words (please give a word count) and no more than five references (including one to the BMJ article to which they relate); references should be in the Vancouver style. We welcome pictures.

Letters should be typed and signed by each author, and each author's current appointment and address should be stated. We encourage you to declare any conflict of interest. Please enclose a stamped addressed envelope if you would like to know whether your letter has been accepted or rejected.

We may post some letters submitted to us on the world wide web before we decide on publication in the paper version. We will assume that correspondents consent to this unless they specifically say no.

Letters will be edited and may be shortened. faecal occult blood. The authors suggest that barium studies of the gastrointestinal tract are adequate. We would argue that gastrointestinal endoscopy should always be used because it allows small mucosal lesions to be seen, blood loss to be estimated directly, and biopsy samples to be taken (particularly from the second part of the duodenum for coeliac disease), which we consider mandatory. For similar reasons, a case can also be made for colonoscopy rather than barium enema, but, in hospitals that do not have a colonoscopist who almost always reaches the caecum, a double contrast barium enema can be used as a screening test.

As the authors say, the challenge in diagnosing iron deficiency is determining the cause of the anaemia. Diagnoses such as hiatus hernias, haemorrhoids, and colonic diverticular disease are usually coincidental rather than causative. In patients with gastrointestinal bleeding who do not have an obvious lesion after investigation of the upper and lower gastrointestinal tract, enteroscopy may show lesions in the small intestine, where small bowel radiology usually fails. ${ }^{4}$ A group of patients remains in whom investigation of the upper and lower gastrointestinal tract cannot identify the bleeding site, and most of these patients have a benign course. ${ }^{5}$

W P Goddard Senior registrar

I Murray Research registrar

R G Long Consultant gastroenterologist

Department of Gastroenterology, Nottingham City Hospital, Nottingham NG5 1PB

1 Frewin R, Henson A, Provan D. ABC of clinical haematology. Iron deficiency anaemia. BMJ 1997;314:360-3.

2 Sayer JM, Long RG. A perspective on iron deficiency anaemia. Gut 1993;34:1297-9.

3 McIntyre AS, Long RG. Prospective survey of investiga3 McIntyre AS, Long RG. Prospective survey of investiga-
tions in outpatients referred with iron deficiency anaemia. tions in outpatients refe.

4 Davies GR, Benson MJ, Gertner DJ, Van Someren RMN, Rampton DS, Swain CP. Diagnostic and therapeutic push type enteroscopy in clinical use. Gut 1995;37:346-52.

5 Sahay R, Scott BB. Iron deficiency anaemia-how far to investigate? Gut 1993;34:1427-8.

\section{Limit investigations if iron deficiency has} no obvious cause

EDITOR-It was interesting to read about iron deficiency anaemia from a haematologist's perspective. ${ }^{1}$ As a gastroenterologist who sees a lot of patients with iron deficiency anaemia, I would like to make several comments.

Firstly, the finding of faecal occult blood is of doubtful value in this situation. If a colonic carcinoma or a polyp is suspected then it should be sought directly by barium enema or colonoscopy rather than by looking for the bleeding that might be caused by such lesions.

Secondly, coeliac disease should be specifically sought by small bowel biopsy in patients with no obvious cause of iron deficiency. I detect two or three cases of coeliac disease each year among patients investigated for iron deficiency.

Thirdly, gastroenterologists would need convincing that microscopic haematuria is a sufficiently common cause of iron deficiency anaemia for them to recommend routine examination of a mid-stream specimen of urine.

Fourthly, pelvic ultrasonography would be helpful only if there was menorrhagia. I doubt that it would be of any value in other situations of iron deficiency anaemia.

Lastly, hiatus hernia is not a cause of iron deficiency anaemia except possibly when there is associated oesophagitis or peptic ulceration. Since both these other conditions are mentioned in the list of bleeding gastrointestinal causes of iron deficiency anaemia I do not think that the addition of hiatus hernia is sensible.

Sahay and I have shown that it is safe to limit investigation of patients with iron deficiency of no obvious cause to upper gastrointestinal endoscopy, small bowel biopsy, and barium enema. ${ }^{2}$

Brian Scott Consultant physician County Hospital, Lincoln LN2 5QY

1 Frewin R, Henson A, Provan D. ABC of clinical haematology. Iron deficiency anaemia. BM] 1997;314:360-3. (1 February.)

2 Sahay R, Scott BB. Iron deficiency anaemia-how far to investigate? Gut 1993;34:1427-8.

\section{Patients must be screened for coeliac disease}

Editor-Rebecca Frewin and colleagues suggest that if there is no obvious source of blood loss in patients with iron deficiency anaemia then investigations should include tests for faecal occult blood. ${ }^{1}$ I believe this approach to be incorrect. If the result of the faecal occult blood test is positive, investigation of the gastrointestinal tract is mandatory. If the result is negative, investigation of the gastrointestinal tract remains mandatory, since many gastrointestinal cancers and colorectal polyps bleed intermittently. Thus testing for faecal occult blood has little relevance in the initial investigation of iron deficiency anaemia.

The article also omits to mention the value of screening for coeliac disease, which is a not uncommon cause of iron deficiency 
anaemia; screening should be with tests for antibodies to gliadin and endomysium ${ }^{2}$ or duodenal biopsy, or both.

Finally, an uncomplicated hiatus hernia does not cause anaemia. Although oesophagitis may cause iron deficiency anaemia, most gastroenterologists would investigate the remainder of the gastrointestinal tract in a patient with iron deficiency and oesophagitis. Indeed, in a recent Lesson of the Week two of eight patients with concomitant disease (colorectal carcinoma in all cases) had erroneously had their anaemia ascribed to oesophagitis. ${ }^{3}$

Roger Barton Reader

Department of Medicine, NorthTyneside General Hospital, North Shields NE29 8NH

1 Frewin R, Henson A, Provan D. ABC of clinical haematology. Iron deficiency anaemia. BMJ 1997;314:360-3. (1 February.)

2 McMillan SA, Haughton DJ, Biggart JD, Edgar JD, Porter KG, McNeill TA. Predictive value for coeliac disease of antibodies to gliadin, endomysium, and jejunum in antibodies to gliadin, endomysium, and jejunum in
patients attending for jejunal biopsy. BMJ 1991;303: patients

3 Till ASH, Grundman MJ. Prevalence of concomitant Till ASH, Grundman MJ. Prevalence of concomitant
disease in patients with iron deficiency anaemia. BMJ 1997;314:206-8. (18 January.)

\section{Is important in young children}

EDITOR-I found the review on iron deficiency anaemia informative, but, as usual in general reviews, the paediatric angle was unsatisfactory. ${ }^{1}$ As the $B M J$ is a general medical journal with a wide readership I expect its general reviews to include a section on the important paediatric issues relevant to the topic discussed.

Iron deficiency anaemia is common in toddlers, with a widely quoted prevalence of $10 \%$; the figure is even higher in some inner city areas. The condition causes appreciable morbidity. Dietary deficiency of iron is the commonest cause for it in developed countries. Besides many of the symptoms and signs mentioned in the review, iron deficiency anaemia may also cause psychomotor retardation in toddlers. This is correctable with iron supplementation. Iron plays an important part in normal brain function, especially during the development of the brain

Iron deficiency anaemia in children matters on both an individual and a public health level. It warrants publicity as it is a highly prevalent problem and one of the few treatable causes of psychomotor retardation in childhood.

Michael Salman Lecturer

Paediatric Neurosciences, King's College Hospital, London SE5 9RS

1 Frewin R, Henson A, Provan D. ABC of clinical haematology. Iron deficiency anaemia. BMJ 1997;314:360-3 (1 February.)

\section{Authors' reply}

EDITOR-In general terms the ABC series attempt to provide an overview of a specialty for junior doctors, general practitioners, and other non-specialists. We were disappointed that W P Goddard and colleagues found our article superficial, but within the confines of articles in the series (1500 words) it is extremely difficult to cover each topic exhaus- tively. When authors are commissioned they are asked to keep articles within a strict word length and to make articles didactic-hence the textbook style of the series.

In the original version of our article we omitted rare clinical features such as koilonychia and oesophageal or pharyngeal webs in iron deficiency. The reviewer, however, thought that these should be included. We agreed to this, bearing in mind the function of the articles and intended audience. At the same time we fully accept that some of these features are uncommon in clinical practice.

Faecal occult blood testing is controversial, and there have been numerous reports of its use as a screening tool in colorectal cancer. ${ }^{1}$ We would concede with Goddard and colleagues that this simple investigation has been largely superseded by direct visualisation of the gastrointestinal tract; most clinicians refer patients for upper or lower gastrointestinal endoscopy when this seems appropriate.

Coeliac disease was discussed in our article, but we had insufficient space to cover it in any great detail. Although urea and electrolyte concentrations and liver function tests are unlikely to be of direct value in the diagnosis of iron deficiency, most clinicians would probably perform them at the initial consultation. ${ }^{2}$ Pelvic ultrasonography was listed as an investigation in females "if indicated." By this we meant when there was a history of menorrhagia or other clinical indications. We accept that uncomplicated hiatus hernia is an unlikely cause of iron deficiency anaemia, but it becomes more likely if there is associated ulceration or oesophagitis.

In response to Michael Salman, we are well aware of the paediatric problems associated with iron deficiency and, in particular, psychomotor retardation. ${ }^{3}$ Due to severe space constraints we were unable to discuss this. In addition this series deals primarily, though not exclusively, with adult disorders.

\section{Rebecca Frewin Registrar}

Drew Provan Consultant

Department of Haematology, Southampton University Hospitals NHS Trust, Southampton SO16 6YD

Andrew Henson Clinical research fellow

University Department of Primary Care, Royal

South Hants Hospital, Southampton SO14 OYG

1 Simon BJ. Occult blood screening for colorectal carcinoma: a critical review. Gastroenterology 1995;88:820-7.

2 McIntyre AS, Long RG. Prospective survey of investigations in outpatients referred with iron deficiency anaemia. Gut 1993;34:1102-7.

3 Oski FA. Iron deficiency in infancy and childhood. N Engl J Med 1993;329:190-3.

\section{More teenagers seem to be seeking contraceptive advice from their general practitioner}

EDITor-The In brief section of the News reported a study commissioned by Durex suggesting that fewer teenagers were going to their general practitioner for sexual health advice. ${ }^{1}$ Only $19 \%$ of the $16-17$ year olds said that they were going to their general practitioner compared with $37 \%$ the previous year. These results are not borne out by the experience in general practice.

I have been trying for several years to dispel the myth that teenagers are not going to their general practitioners. In 1994 Pereira Gray and I showed that over half of those aged 16-19 in our two very different practices, one city based and one semi-rural, attended for contraceptive advice. ${ }^{2}$ In that study $72(44 \%)$ of the 165 patients aged 16 and 17 registered with the Honiton Group Practice had attended.

I repeated the analysis of the girls in Honiton aged 16 and 17 in the middle of 1996 and found that $80(49 \%)$ of the 162 girls had seen a general practitioner for contraceptive advice. A further 5\% had sought advice for period problems or acne and were asked about their contraceptive needs, but they said that they needed none at present, although some were prescribed the combined pill for their medical condition. These data imply that increasing rather than decreasing numbers of teenagers are seeking advice from their general practitioners, and I am sure that this is not just in Honiton.

Clare J Seamark General practitioner

The Surgery, Honiton, Devon EX14 8DD

1 Anonymous. Fewer people look to GPs for sexual health advice. BMJ 1997;314:536. (22 February.)

2 Seamark CJ, Pereira Gray DJ. Do teenagers consult general practitioners for contraceptive advice? British Journal of Family Planning 1995;21:50-1.

\section{Increased parity and risk of trisomy 21}

Study measured prevalence of Down's syndrome at birth, not incidence

Editor-Michael S Schimmel and colleagues state that the incidence of Down's syndrome is 1.46 per 1000 live births when they mean the prevalence at birth. ${ }^{1}$ The accompanying commentary claims that the authors used prevalence as a proxy for incidence on the grounds that there were no terminations because the community eschewed prenatal diagnostic services. The authors do not make this claim, but even if they did it is not valid. Assuming that there were no terminations for Down's syndrome, it is still valid only to determine the prevalence at birth because there is no means of knowing how many conceptuses with Down's syndrome were spontaneously aborted. A disproportionate number of spontaneous abortions are chromosomally abnormal and a significant proportion of conceptuses with Down's syndrome are spontaneously aborted. Hypothetically, as a woman's parity and age increase she could become less efficient at "recognising" and spontaneously aborting a conceptus that has Down's syndrome. If this were so the prevalence at birth cannot be a proxy for incidence.

The authors may have shown an increase in the birth prevalence of Down's syndrome with increasing parity which is 
independent of age, but they have not provided any evidence for a parity effect on incidence. The distinction between incidence and prevalence is paramount when considering the aetiology of any condition.

P O D Pharoah Head

Department of Public Health, University of

Liverpool, Whelan Building Quadrangle, Liverpool L69 3GB

1 Schimmel MS, Eidelman AI, Zadka P, Kornbluth E, Hammerman C. Increased parity and risk of trisomy: a
review of 37110 live births. [With commentary by RJ Lilford.] BMJ 1997;314:720-1. (8 March.)

\section{Authors' reply}

EDITOR-We thank P O D Pharoah for the opportunity to clarify our presentation on the incidence of Down's syndrome. As we noted in the article, there was an increased incidence in the birth of infants with Down's syndrome in mothers with high parity in a population in which termination of pregnancy was essentially zero. In addition, to our knowledge there are no data to suggest that increasing parity affects the rate of spontaneous abortions. Thus, we think that our data truly reflect the incidence at birth, though not necessarily the incidence at conception.

Arthur I Eidelman Professor of paediatrics

Department of Neonatology, Shaare Zedek Medical Centre, PO Box 3235, Jerusalem, Israel 91031

Pnina Zadka Senior epidemiologist

Health Division, Israel Central Bureau of Statistics, Jerusalem

\section{Brain damage in divers}

\section{The risk has been underestimated}

EDITOR-Using magnetic resonance imaging Michael Knauth and colleagues reinforce the message that scuba diving is a dangerous sport $^{1}$; they show images of some small areas of brain damage found in apparently normal participants. I think that they have greatly underestimated the amount of damage and are wrong to criticise the findings of Reul et al, whose study included greatly enlarged perivascular spaces as lesions. ${ }^{2}$ Knauth and colleagues cite a paper by Jungreis et al which suggested that such fluid filled spaces may be of no pathological significance ${ }^{3}$; however, these findings applied to people of stroke age in whom such spaces are indeed significant but should not be confused with lacunar infarcts. Healthy people with a mean age of 35.7 years whom Knauth and colleagues studied do not show large widely scattered perivascular spaces.

In his editorial in the same issue Peter Wilmshurst $^{4}$ refers to a paper by my colleagues and me, in which we reported the histological study of many small lesions in scuba and young professional divers. ${ }^{5}$ Distension of the perivascular space was always associated with local destruction of the arterial muscle coat and elastic lamina, leaving a length of vessel of hyaline and collagen. Sometimes the artery or arteriole was itself dilated at that point. Because the lesions appeared abruptly in an otherwise normal length of vessel we presumed that they were the result of acute local luminal hypertension-the effect of a ballooning bubble of gas. I have seen similar lesions in people under 45 in cases of phaeochromocytoma and maternal eclampsia, in which patches of destruction of an arterial wall and microaneurysms occur as a focal response to surges of very high general blood pressure.

The aetiology may be different in these conditions but the pathogenesis of the effect on the mental state is much the same. Apart from direct local damage to brain tissue, it includes permanent interruption of local vasomotor control and inadequate redistribution of blood to areas of the brain associated with thought.

Peter O Yates Emeritus professor of neuropathology Silverdale, Carnforth, Lancashire LA5 0TP

1 Knauth M, Ries S, Pohimann S, Kerby T, Forsting M, Daffertshofer M, et al. Cohort study of multiple brain lesions in sport divers: role of a patent foramen ovale. $B M J$ 1997;314:701-5. (8 March.)

2 Reul J, Weis J, Jung A, Willmes K, Thron A. Central nervous system lesions and cervical disc herniations in amateur divers. Lancet 1995;345:1403-5.

3 Jungreis CA, Kanal E, Hirsch WL, Martinez AJ, Moossy J. Normal perivascular spaces mimicking lacunar infarction. Radiology 1988;169:101-4.

Rilm 1988,169.101-4. 90. (8 March.)

5 Palmer AC, Calder IM, Yates PO. Cerebral vasculopathy in Palmer AC, Calder IM, Yates PO. Cerebral vasculo
divers. Neuropathol Appl Neurobiol 1992;18:113-24.

Cross sectional studies are inconclusive, longitudinal studies are more appropriate

EDITOR-Peter Wilmshurst justifiably urges caution $^{1}$ in interpreting Michael Knauth and colleagues' report of brain lesions in divers. ${ }^{2}$ The report describes a cross sectional study of a cohort of 87 sports divers of whom 25 were deduced to have right-to-left intracardiac or intrapulmonary shunts on the basis of Doppler monitoring of the middle cerebral artery. Three out of 11 divers with haemodynamically relevant shunts were reported to have multiple hyperintense areas on magnetic resonance imaging confined to the territory of the anterior cerebral artery.

The clinicopathological significance of the reported changes on magnetic resonance imaging is unknown, but all divers were symptom free and had no history of type 2 decompression sickness (presumably no neurological or cardiopulmonary symptoms). Presence or absence of a history of other forms of decompression illness is not stated. The three divers with multiple changes on magnetic resonance imaging were all in their 40s and somewhat older than the mean for the cohort ( 35.7 years; SD 8.9). Their sex is not stated.

A cross sectional study cannot exclude other causes for the reported appearances on magnetic resonance imaging; the findings may merely depict the cerebral effects of a lifetime of venous emboli (including bubbles) that have crossed a right-to-left shunt. In their discussion the authors discount a thromboembolic pathogenesis by citing a previous study comparing divers with non-diving controls, ${ }^{3}$ yet in their next paragraph they admit that study's unreliability because of selection bias.

Although we appreciate the difficulties in designing a study of this sort, all the above points and the lack of non-diving controls make the results difficult to interpret. From a pragmatic standpoint, all that can be concluded is that the finding of a significant right-to-left shunt in a diver has a sensitivity of $23 \%$ and unknown specificity for predicting changes on magnetic resonance imaging that have a debatable aetiology and an unknown clinical significance. None the less, this report will cause concern among both professional and recreational divers.

Further cross sectional studies will add little more to our knowledge and will neither confirm nor allay concerns about the health effects of right-to-left shunts in divers. A sizeable and appropriately controlled longitudinal prospective study is the only way ahead.

J R Broome Senior medical officer in hyperbaric medicine

A D Pitkin Civilian medical practitioner in undersea medicine

Institute of Naval Medicine, Undersea Medicine Division, Gosport, Hampshire PO12 2DL

1 Wilmshurst P. Brain damage in divers. BMJ 1997;314:68990. (8 March.)

2 Knauth M, Ries S, Pohimann S, Kerby T, Forsting M, Daffertshofer M, et al. Cohort study of multiple brain lesions in sport divers: role of a patent foramen ovale. $B M J$ in sport divers: role of a parch.)

3 Reul J, Weis J, Jung A, Willmes K, Thron A. Central nervous system lesions and cervical disc herniations in amateur divers. Lancet 1995;345:1403-5.

\section{Authors' reply}

EDITOR-We thank Peter O Yates and J R Broome and A D Pitkin for their remarks. The neurological sequelae in professional divers shown by Todnem et al, ${ }^{1}$ the finding of cerebral vasculopathy in divers by Palmer et $\mathrm{al}^{2}{ }^{2}$ and the increased prevalence of brain lesions in sport divers shown by Reul et $\mathrm{al}^{3}$ justify concern among professional and recreational divers. Our findings and those of Wilmshurst et $\mathrm{al}^{4}$ underscore the relevance of a patent foramen ovale in the development of multiple brain lesions and the occurrence of type 2 decompression sickness, respectively. Although the divers with brain lesions in our study did not have overt neurological symptoms, common sense suggests caution.

A thromboembolic pathogenesis of the brain lesions is unlikely, because in that case brain lesions should have been evenly distributed between divers and controls in the study of Reul et al; a hypothetical selection bias in the study by Reul et al cannot entirely explain the dramatic difference in the prevalence of brain lesions between divers and controls. ${ }^{3}$ Furthermore, the multiple small brain lesions in the subcortical and central white matter seen in the divers had a characteristic appearance on cerebrovascular examination and are an unusual finding in patients with a patent foramen ovale.

We chose a conservative approach in defining brain lesions by excluding widened perivascular spaces and focusing solely on intraparenchymal signal abnormalities. We agree with Yates that there might be tissue destruction in the vicinity of widened perivascular spaces. However, as we could not detect intraparenchymal signal abnor- 
malities in the surrounding areas of widened perivascular space, we did not feel comfortable labelling widened Virchow-Robin spaces as brain lesions. The finding of cerebral vasculopathy in about $30 \%$ of the divers suggests that there might be more damage to the brains of divers than that described by us. The pathogenesis of the vessel abnormalities suggested by Yates would also require a patent foramen ovale, as intra-arterial bubble formation is highly uncommon during diving.

Although we know about the limitations of a single study, we believe that the evidence that has been accumulated by both our study and others should lead to discussions on how to minimise the health hazards of diving.

Michael Knauth Neuroradiologist

Department of Neuroradiology, University of

Heidelberg Medical School, Im Neuenheimer Feld 400, D 69120 Heidelberg, Germany

Stefan Ries Neurologist

Department of Neurology, Klinikum Mannheim,

University of Heidelberg Medical School,

Theodor-Kutzer-Ufer, D 68135 Mannheim,

Germany

1 Todnem K, Skeidsvoll H, Svihus R, Rinck P, Riise T, Kambestad BK, et al. Electroencephalography, evoked potentials and MRI brain scans in saturation divers. An popidemiological study. Electroencephal Clin Neurophysiol
1991;79:322-9.

2 Palmer AC, Calder IM, Yates PO. Cerebral vasculopathy in divers. Neuropathol Appl Neurobiol 1992;18:113-24.

3 Reul J, Weis J, Jung A, Willmes K, Thron A. Central nervous system lesions and cervical disc herniations in amateur divers. Lancet 1995;345:1403-5.

4 Wilmshurst PT, Byrne JC, Webb-Pepploe MM. Relation between interatrial shunts and decompression sickness in divers. Lancet 1989;ii:1302-5.

\section{Consent procedure for coronary angioplasty is haphazard}

EDITOR-A legal case highlighted the importance of patients giving fully informed consent for medical procedures. ${ }^{1}$ Doctors must inform the patient of significant risks, but what represents a significant risk for particular procedures is not precisely defined. ${ }^{2}$ Coronary angioplasty carries a risk of death in hospital and of emergency coronary artery bypass grafting of $0.7 \%$ and $1.1 \%$ respectively. ${ }^{3}$

To assess current British practice when informed consent is obtained for coronary angioplasty we conducted a telephone survey of 25 centres in England, Scotland, and Wales that regularly performed the procedure. We asked junior cardiology staff (23 senior house officers, one house physician, and one senior registrar), who gained patients' consent for coronary angioplasty, five questions relating to patients having routine coronary angioplasty: who routinely obtained consent; whether a specific cardiology/coronary angioplasty or routine hospital consent form was used; whether written information was supplied; whether patients were warned of the risk of death or coronary artery bypass grafting; and the probability quoted for these risks (table).

Although senior medical staff usually discuss coronary angioplasty with patients,
Responses of 25 junior medical staff to

questions regarding consent for routine coronary angioplasty (PTCA)

\begin{tabular}{lc} 
& No \\
\hline Who obtained consent for routine PTCA: & \\
\hline Senior house officer & 23 \\
\hline House physician & 1 \\
\hline Senior registrar & 1 \\
\hline Specific consent form used: & 4 \\
\hline Yes & 21 \\
\hline No & 16 \\
\hline Written information given: & 9
\end{tabular}

Warned of possibility of death or CABG:

\begin{tabular}{lc}
\hline Both & 17 \\
\hline CABG only & 8 \\
\hline Estimate of risk given: & \\
\hline None routinely & 12 \\
\hline $0.1 \%$ & 3 \\
\hline $0.4-1 \%$ & 1 \\
\hline $1 \%$ & 4 \\
\hline$\geqslant 1 \%$ & $5^{*}$
\end{tabular}

${ }^{*}$ Risk of $1-2 \%$ given by two, of $1-3 \%$ by one, of $3-4 \%$ by one, and of $1-5 \%$ by one.

senior house officers usually obtain written consent. It is important that they are able to give an accurate estimate of the risks and routinely mention those considered to be significant. The need to inform patients about a particular risk depends on its probability and severity. ${ }^{2}$ In our survey eight of the doctors did not routinely warn of the risk of death, although all warned of the risk of emergency coronary artery bypass grafting, despite similar probabilities. The probability quoted ranged widely. Although patients' risks vary, we asked only about routine cases, so this range is surprising. Perhaps many doctors minimise the quoted risk to avoid worrying patients or deterring them from having coronary angioplasty. This may also account for the 12 doctors who did not give the probability unless asked. Providing fuller information about risks does not, however, necessarily increase anxiety, ${ }^{4}$ while underestimation of risk prevents fully informed consent being obtained. ${ }^{2}$ Patients' retention of information may be improved by the provision of written details. ${ }^{5}$ Nine centres did not provide written information, which suggests that communication is not optimal.

Our findings highlight the haphazard nature of the consent procedure for coronary angioplasty. Greater standardisation would allow easier identification of accepted practice. With improved collection of data, more accurate estimation of risk could eliminate the wide variation quoted. The magnitude of risk warranting routine mention also needs to be established. Written information, provided by most centres, improves patients' understanding and should be considered to be standard practice.

Edward Langford Specialist registrar

Adam de Belder Senior registrar

Department of Cardiology, King's College Hospital, London SE5 9RS
1 Bolam v Friern Hospital Management Committee 1WLR 582.

2 Brahams D. Doctor's duty to inform patient of substantial or special risks when offering treatment. Lancet 1985;i:528-30. 3 Altmann DB, Racz M, Battleman DS, Bergman G, Spokojny A, Hannan EL, et al. Reduction in angioplasty complications after the introduction of coronary stems: results from a consecutive series of 2242 patients. Am Heart J 1996;132:503-7.

4 Kerrigan DD, Thevasagayam RS, Woods TO, McWelch I, Thomas WEG, Shorthouse AJ, et al. Who's afraid of informed consent? BMJ 1993;306:298-300.

5 Layton S, Korsen J. Informed consent in oral and maxillofacial surgery: a study of the value of written warnings. $\mathrm{Br} J$ Oral Maxillofac Surg 1994;32:34-6.

\section{Informed participation in screening is essential}

EdiToR-A paradox with early detection is that its popularity bears little relation to the magnitude of its benefits and harms. Sarah Stewart-Brown and Andrew Farmer's editorial about screening could therefore be dismissed by some people as public health negativism. ${ }^{1}$ There is sparse evidence that subjects suffer psychological morbidity, so why worry?

Consider what happens when we screen 250000 women for cervical cancer. The aim is to help a subset of the 40 or so women who would die annually of cervical cancer among this number. It can only be a subset because not all cases are detectable through screening, and not all those detected are amenable to cure even if found early. Among those patients tested we find newly abnormal smears in some $15500 .^{2}$ All but a few hundred (that is, the number of incident serious cases during a screening round of five years) represent overdetection. In other words, over 15000 women have abnormal cytological findings but would never have a problem from cervical cancer. Through screening we have given them a problem. Yet most of these women think they are lucky, believing that they would have died without screening.

Then there are women who have disease detected on screening, receive treatment, yet still develop recurrent disease. ${ }^{3}$ We have made no real difference to their destiny except to make them angry and litigious. Paradoxically they too are firm supporters of screening but believe that someone must have made a mistake in their case. Much the same happens with the women who develop symptomatic disease between screening tests. Their disappointed expectations are an inevitable part of screening, yet these women blame the screeners, not the screening. They will happily campaign for more screening in the belief that if we invested more we could make screening perfect. By offering screening to 250000 we have helped a few, harmed thousands, disappointed many, used $£ 1.5 \mathrm{~m}$ each year, and kept a few lawyers in work. But the women believe that thousands of lives have been saved and that more could be if only so many "mistakes" were not made. Yet cervical cancer is theoretically an ideal disease for prevention through early detection. 
Simplistic beliefs about the power, ease, and affordability of early detection are widespread. This is evident from both reactions to the giving of evidence based information to potential recipients ${ }^{4}$ and the uncritical acceptance of flawed conclusions based on uncontrolled observation of screening. ${ }^{5}$ It is pointless to ask about the harm done by screening until we have asked whether recipients have been given accurate information.

A E Raffle Consultant in public health medicine Avon Health Authority, Bristol BS2 8EE

1 Stewart-Brown S, Farmer A. Screening could seriously damage your health. BMJ 1997;314:533-4. (22 February.)

2 Raffle AE, Alden B, Mackenzie EFD. Detection rates for abnormal cervical smears: what are we screening for? Lancet 1995;345:1469-73.

3 Kolstad P, Klem V. Long- term follow up of 1121 cases of carcinoma in situ. Obstet Gynecol 1976;48:125-9.

4 Oliver S, Rajan L, Turner H, Oakley A, Entwistle V, Watt I, et al. Informed choice for users of health services: views on et al. Informed choice for users of health services: views on
ultrasonography leaflets of women in early pregnancy, ultrasonography leaflets of women in early pregnancy,
midwives, and ultrasonographers. BMJ 1996;313:1251-5. midwives, and ultrasonographers. $B M J 1996 ; 313: 1251-5$.
Cannistra SA, Niloff JM. Cancer of the uterine cervix. N Engl J Med 1996;334:1030-8.

\section{Wait for further evidence confirming effect of interferon beta in multiple sclerosis}

EDitor-The debate about the value of interferon beta in multiple sclerosis will continue until there is sufficient evidence to settle the question beyond doubt. The authors of the various letters in the $B M J$ have largely adopted debating positions that reflect their acknowledged conflicts of interest. ${ }^{1}$ I acknowledge my own conflict of interest but wish to reiterate concerns about conflicts of evidence. $^{23}$

Briefly, subcutaneous interferon beta causes side effects that prevented adequate blinding of patients and may have contributed to the reporting of fewer relapses in patients treated with interferon beta-lb than with placebo. The reduction in lesion load on T2 weighted magnetic resonance imaging after two and three years that was seen with interferon beta-lb was not confirmed with interferon beta-la. The reduction in the development of disability with interferon beta-1a was measured with the lower part of the Kurtzke expanded disability status scale, which reflects impairment rather than disability, and was not observed with interferon beta-lb.

Peter Cardy has as much right as any neurologist to point out the devastating effect that relapses may have in some patients. ${ }^{1}$ As he pointed out in his earlier letter, however, we do not have information on the relative value that patients place on reducing relapses compared with slowing progression of disability. ${ }^{4}$ The compassion and humanity for which Peter Cardy appeals may be better served by our waiting a few more months to find out whether the promising results with these interferons can be replicated. Premature adoption of interferon beta risks obscuring the truth and causing patients to inject themselves with a drug that certainly has side effects but does not certainly offer long term benefits. Patients with multiple sclerosis, their neurologists, and pharmaceutical companies will be able to argue much more powerfully for provision of the drug if the evidence can be confirmed.

Richard Hughes* Professor of neurology UMDS, Guy's Hospital, London SE1 9RT

* Richard Hughes is participating in trials of interferon beta-la in multiple sclerosis funded by Ares Serono.

1 Interferon beta in multiple sclerosis [letters]. BMJ 1997;314:600-2. (22 February.)

2 Hughes RAC. Immunotherapy for multiple sclerosis. J Neurol Neurosurg Psychiatry 1994;57:3-6.

3 Hughes RAC, Sharrack B. More immunotherapy for multiple sclerosis. J Neurol Neurosurg Psychiatry 1996;61:239-41. Cardy P. Use of interferon beta $1 \mathrm{~b}$ for multiple sclerosis. BMJ 1996;313:1263. (16 November.)

\section{Deaths related to methadone have doubled in Lothian seep 1730}

Editor-In Lothian in the late 1970s injecting drug use increased rapidly. In an attempt to eradicate this the availability of needles and syringes was severely restricted. One consequence of this policy was that in the early ' 80 s the newly arrived HIV infection spread rapidly among injecting drug users who had been deprived of injecting equipment.

In the mid-eighties methadone began to be prescribed to drug misusers who were HIV positive, and needles and syringes were made widely available to reduce the risk of onward transmission of HIV. By 1988 the Community Drug Problem Service in partnership with general practitioners had introduced methadone treatment for noninfected drug misusers. ${ }^{2}$

Subsequently, the proportion of new referrals to the service who had ever injected fell from $97 \%(88 / 91)$ in 1988 to $43 \%$ (162/ 377 ) in 1993. The proportion of injecting drug users who had injected in the month before referral fell from $88 \%(80 / 91)$ to $14 \%$ $(53 / 377)$ in the same period. The rate of HIV infection in new referrals who had been tested fell from $21 \%(15 / 72)$ in 1988 to $8 \%$ $(11 / 37)$ in $1993 .^{3}$

Currently, the Scottish Office is funding twin projects in Lothian and Glasgow to investigate drug related deaths. Preliminary figures from the Lothian study indicate that between 1995 and 1996 deaths in drug misusers increased by about $50 \%$ and deaths related to methadone (often in combination with other drugs) have more than doubled. A similar trend has been reported in Manchester. ${ }^{4}$ In Lothian a large proportion of these deaths seem to occur in people who have not been prescribed methadone.

This diversion of prescribed methadone presents a fundamental public health dilemma. Large gains have been achieved in preventing HIV infection and the other hazards of illegally injecting drugs (hepatitis $\mathrm{C}$, crime, etc) but at the cost of new deaths due in part to the intervention itself.

Urgent action is now being taken to avoid a reversal of confidence in a programme which undoubtedly saves lives in the right circumstances. Details of the deaths are being investigated and possible changes considered-in particular, a policy of supervised consumption of prescribed methadone at pharmacies, as adopted by the Glasgow Drug Problem Service (see $\mathrm{p}$ 1730). This would be accompanied by a parallel strategy to educate drug misusers about the dangers of methadone to those who are non-opiate tolerant.

Judy Greenwood Consultant psychiatrist Community Drug Problem Service, Royal Edinburgh Hospital, Edinburgh EH10 5HF

Helen Zealley Director of public health

Dermot Gorman Consultant in public health medicine

Lothian Health, Edinburgh EH8 9RS

Paul Fineron Senior lecturer in forensic medicine Tim Squires Research fellow

Forensic Medicine Unit, Department of Pathology, University of Edinburgh, Edinburgh EH8 9AG

1 Robertson JR, Bucknall ABV, Welsby PD, Roberts JJK, Inglis JM, Peutherer JF, et al. Epidemic of AIDS related virus (HTLV-111.LAV) infection among intravenous drug abusers. BMJ 1986;292:527-9.

Greenwood J. Creating a new drug service in Edinburgh BMJ 1990;300:587-9

Greenwood J. Six years' experience of sharing the care of Edinburgh's drug users. Psychiatric Bulletin 1996;20:8-11.

4 Cairns A, Roberts ISD, Benbow EW. Characteristics of fatal methadone overdose in Manchester, 1985-94. BMJ 1996; 313:264-5.

\section{Increased house dust mite allergen in synthetic pillows may explain increased wheezing}

EDIToR-The letter by David Strachan and Iain M Carey examining the increased risk of wheezing associated with synthetic pillows seems confusing. ${ }^{1}$ It is not clear whether they have used whole mite extract or why they used $1 \mathrm{~mm}$ diameter weals as a cut off point when this will include non-atopic children. However, the increased risk of wheezing associated with synthetic pillows is potentially important, given the intimate contact with pillows.

We have shown that synthetic pillows have eightfold higher amounts of Der $p$ I than feather pillows. ${ }^{2}$ Peat et al and Custovic et al have shown a clear dose-response relation between amounts of $\operatorname{Der} p \mathrm{I}$ in the home and current asthma symptoms. ${ }^{3}{ }^{4}$ Therefore an eightfold variation in total $\operatorname{Der} p \mathrm{I}$ in an allergen reservoir on which people rest the access to their airways every night might be relevant.

We have subsequently examined the accumulation of $\operatorname{Der} p$ I in new synthetic and feather pillows and confirmed our previous findings. We placed a pair of new synthetic and feather pillows on the same beds in 12 homes. After four months the synthetic pillows yielded a geometric mean concentration of $7.03 \mu \mathrm{g}$ Der $p \mathrm{I} / \mathrm{g}$ fine dust $(95 \%$ confidence interval 3.41 to 14.49 ) and feather pillows $1.09 \mu \mathrm{g}$ Der $p \mathrm{I} / \mathrm{g}$ (0.15 to 2.18) $(\mathrm{P}=0.0001)$. Corresponding values at the start of the study were $1.83 \mu \mathrm{g} / \mathrm{g}(0.15$ to 4.88) for synthetic pillows and $0.67 \mu \mathrm{g} / \mathrm{g}$ (0.36 to 1.60$)$ for feather pillows.

The increased exposure to house dust mite allergen from synthetic pillows may explain the increased asthma symptoms. How- 
ever, there remains the possibility that part of the reason lies in bias associated either with a switch to synthetic pillows by parents of asthmatic children or with parents of asthmatic children always having used synthetic pillows for their asthmatic child. In trying to reduce this bias Strachan and Carey may not have excluded children by asking parents if they had made "alterations to the child's bedroom ...."

Julian Crane Professorial research fellow

Trudi Kemp Senior research fellow

Robert Siebers Senior technical officer

Natalie Rains Research assistant

David Fishwick Senior research fellow

Penny Fitzharris Clinical allergist

Wellington Asthma Research Group, Wellington

School of Medicine, Wellington, New Zealand

1 Strachan D, Carey I. Reduced risk of wheezing in children using feather pillows is confirmed. BMJ 1997;314:518. (15 February.)

2 Kemp T, Siebers R, Fishwick D, O'Grady G, Fitzharris P, Crane J. House dust mite allergen in pillows. BMJ 1996;313:916

3 Custovic A, Taggart S, Francis H, Chapman M, Woodcock A. Exposure to house dust mite allergens and the clinical activity of asthma. J Allergy Clin Immunol 1996;98:64-72.

4 Peat JK, Tovey E, Toelle BG, Haby MM, Gray EJ, Mahmic A, et al. House dust mite allergens. A major risk factor for childhood asthma in Australia. Am J Respir Crit Care Med 1996;153:141-6.

\section{Thyroxine should be tried in clinically hypothyroid but biochemically euthyroid patients}

EDITOR-We wish to question present medical practice, which considers abnormal serum concentrations of free thyroxine and thyroid stimulating hormone-those outside the $95 \%$ reference interval - to indicate hypothyroidism but incorrectly considers "normal" free thyroxine and thyroid stimulating hormone concentrations to negate this diagnosis. ${ }^{1}$ It is unusual for doctors to start thyroxine replacement in clinically hypothyroid but biochemically euthyroid patients.

The free thyroxine and thyroid stimulating hormone concentrations in 80 patients considered to be hypothyroid on established criteria indicated that only five patients had free thyroxine concentrations (just) below the reference interval of 10-19 $\mathrm{pmol} / \mathrm{l}$ (values of 9.4, 9.8, 9.8, 9.9, and $9.9 \mathrm{pmol} / \mathrm{l}$ ) and only four patients had thyroid stimulating hormone values above the reference interval of $0.5-5.5 \mathrm{mU} / 1$ (values of $5.6,8.4,11.8$, and $30.1 \mathrm{mU} / 1)$; moreover in these 80 patients the mean (SE) concentration of free thyroxine was $12.9(0.2) \mathrm{pmol} / \mathrm{l}$ and the mean concentration of thyroid stimulating hormone was $2.2(0.4) \mathrm{mU} / 1$; both of these values lie well within the normal reference intervals. While we accept that there will be subjective variation in the evaluation of clinical diagnostic criteria and that the long term response to thyroid replacement is a prerequisite of our proposition, exclusion of hypothyroidism on the grounds of hormone concentrations measured in the laboratory seems wrong.

We contend that an incremental three month trial of thyroxine treatment in clinically hypothyroid but biochemically euthyroid patients is a safe and reasonable strategy. The dangers of osteoporosis and cardiac catastrophe-particularly during a three month trial-are sometimes quoted, but these worries are unfounded and condemn many patients to years of hypothyroidism with its pathological complications and poor quality of life. We urge that the question of clinical hypothyroidism in biochemically euthyroid patients should be subjected to a formal clinical trial.

Gordon R B Skinner Clinical virologist

Harborough Banks, Old Warwick Road, Lapworth, Warwickshire B94 6LD

R Thomas General practitioner

Old Road Surgery, Llanelli, Carmarthenshire

SA15 3HR

M Taylor General practitioner

9 East Street, Prittlewell, Southend on Sea, Essex SS2 6LQ

M Sellarajah General practitioner

115 Humberstone Road, Pype Hayes, Erdington B24 0PY

S Bolt General practitioner

Westcotes Health Centre, Leicester LE3 0LP

S Krett General practitioner

118 Station Road, Hendon, London NN4 3FN

A Wright General practitioner

57 Chorley New Road, Bolton BL1 4QR

1 Weetman AP. Hypothyroidism: screening and subclinical disease. BMJ 1997;314:1175-78. (19 April.)

\section{Large pragmatic randomised studies of new antiepileptic drugs are needed}

EDITOR-Two letters commenting on our systematic review of trials of new antiepileptic drugs ${ }^{1}$ deserve a response. We agree with A J A Elferink and B J Van Zwieten-Boot that the number needed to treat is a useful statistic, but we believe that they are wrong to suggest that we should have presented it rather than odds ratios. ${ }^{2}$ We had in fact undertaken a risk difference analysis (1/number needed to treat) and found much greater heterogeneity with respect to this statistic. As a consequence we believe it would have been misleading to present numbers needed to treat and suggest that significant differences in efficacy were found between the new antiepileptic drugs. In contrast to single efficacy studies, it is not always appropriate to present the number needed to treat as the primary outcome statistic for a meta-analysis.

M J Brodie makes several points. ${ }^{3}$ We accept that there are limitations to a systematic review of placebo controlled trials designed for regulatory purposes, and we also accept that there are problems with making indirect comparisons. However, no head to head randomised studies comparing new antiepileptic drugs have been undertaken, and a systematic review of placebo controlled studies is the best use of the currently available data. We must point out that Brodie is no stranger to making indirect comparisons between studies of antiepileptic drugs, using poorly defined methodology.
Brodie is right to suggest that different types of seizure may respond to drugs with different mechanisms of action, but there is no hard empirical evidence to support this hypothesis from randomised controlled trials comparing standard antiepileptic drugs, let alone the new antiepileptic drugs. We believe that it is useful for clinicians to know that on average one drug may be twice as likely to produce a useful therapeutic effect as another, otherwise any attempt to use these drugs is mere cookery. Any attempt to marry drugs with certain mechanisms of action with certain types of seizure would require large randomised trials in order to generate large enough subgroups for this interaction to be investigated. Preliminary evidence, of course, may be generated from a meta-analysis of data on individual patients.

As we emphasised in our paper, future progress will require large pragmatic randomised studies, the design of which will be aided by the results of meta-analyses of existing studies.

Anthony Marson Lecturer in neurology Zakaria Kadir Honorary senior registrar David Chadwick Professor of neurology Walton Centre for Neurology and Neurosurgery, University of Liverpool, Liverpool L9 1AE

1 Marson AG, Kadir ZA, Chadwick DW. New antiepileptic drugs: a systematic review of their efficacy and tolerability. BMJ 1996;313:1169-74. (9 November.)

2 Elferink AJA, Van Zweiten-Boot BJ. New antiepileptic drugs. BMJ 1997;314:603. (22 February.)

3 Brodie MJ. New antiepileptic drugs. BMJ 1997;314:602 (22 February.)
(2rodie MJ. New

4 Brodie MJ. Lamotrigine versus other antiepileptic drugs: a star rating system is born. Epilepsia 1994;35(suppl5): S41-6.

\section{Patients from coronary care units should be given their electrocardiograms and carry them at all times}

EDITOR-Our experience with patients admitted with acute chest pain leads us to propose that coronary care units should issue each patient with their electrocardiogram before discharge.

Commonly, patients given thrombolysis are given a thrombolysis card to carry. Possession of an electrocardiogram recorded on the last day of the most recent admission would also be of enormous benefit on any readmission. Often an admitting physician is presented with a patient with prolonged chest pain, a history of ischaemic heart disease and previous myocardial infarction, and suspicious but equivocal electrocardiographic changes. At other times the history is atypical but an electrocardiogram is suggestive of infarction. Often deciding whether chest pains are due to unstable angina or infarction is difficult. Early thrombolysis is of unequivocal benefit in acute myocardial infarction but is not without its risks. A previous electrocardiogram is useful in deciding whether any aberrations such as left bundle branch block or persistent or borderline ST elevation are long standing or due to recent changes. In 
most emergency admissions previous notes are not available, thereby precluding an early conclusion. Comparison of an old electrocardiogram with a recent one can help to clinch the diagnosis and assist management decisions.

We recommend that all patients admitted to coronary care units should be issued with and strongly urged to carry their electrocardiogram at all times. Judgments on their diagnosis will be reached sooner, they will be more likely to receive optimum treatment, and unnecessary administration of thrombolysis with its attendant risks will be avoided. As a spinoff, money will be saved.

Sandeep Varma Senior house officer in general medicine

G Adrian Large Senior house officer in general medicine

Princess of Wales Hospital, Bridgend, Mid

Glamorgan CP31 1RQ

\section{Photograph was insensitive}

EDITOR-Like many psychiatrists to whom I have spoken, I was incensed by the photograph that formed part of a recent article by Clare Dyer. Dyer reported on the publication of the report on Martin Mursell, a schizophrenic man who killed his stepfather and attempted to kill his mother. ${ }^{1}$ The article itself was completely satisfactory and fair. However, the photograph seemed to be of a man, covered by a jacket, who was asleep in a park. I can assume only that the editor of the $B M J$ assumed that this man had schizophrenia and that lying in a park with a coat over him represented "a breakdown of care." Can we assume that the editor knew that this person had schizophrenia? I think not. It seems just as likely that the person was drunk, or perhaps it was the editor of the $B M$ J sleeping off lunch.

Such prejudicial and insensitive attitudes in the $B M J$ do nothing to improve the care of our patients or the profile of what is a greatly misunderstood and misrepresented section of the population.

A J Wilkins Medical director

Redford Lodge Psychiatric Hospital, London N9 9DY

1 Dyer C. Care of schizophrenic man strongly criticised. $B M J$ 1997;314:773. (15 March.)

\section{Editors are justified in asking authors to cite equivalent references from same journal}

EDITOR-Richard Smith's criticism of the editorial judgment of Leukemia, which asked authors to increase the number of references to papers published in Leukemia, ${ }^{1}$ seems harsh in view of the well known Matthew effect. ${ }^{2}$ Merton originally coined this term to describe the frequent misallocation of credit to the more eminent author of coauthored papers, but it can be applied as well to the citation of prestigious journals. Citation behaviour is complex, but most manuscripts involve self citation, and there are many times when any one of several references will satisfy the need for documentation. When either of two alternative references is relevant there may be a tendency to cite the more prestigious source. Moreover, authors write for different audiences and choose their references accordingly. In a manuscript that I have just sent to the $B M J$ I cited a paper published in the Annals of Internal Medicine. In another journal I might have referred to the paper's reprinted version in Current Contents.

Recognising the reality of the Matthew effect, I believe that an editor is justified in reminding authors to cite equivalent references from the same journal, if only because readers of that journal presumably have ready access to it. To call this "manipulation" seems excessive unless the references chosen are irrelevant or mere window dressing.

Eugene Garfield Chairman emeritus Institute For Scientific Information, 3501 Market Street, Philadelphia, PA 19104, USA

1 Smith R. Journal accused of manipulating impact factor. BMJ 1997;314:463. (15 February.)

2 Merton RK. The Matthew effect in science: the reward and communication systems of science. Science 1968;199:55-63.

\section{New Zealand priority criteria project}

This letter was originally published on 12 April (p 1130), but the authors pointed out that we had introduced some errors during editing. Because the errors arose throughout the letter we decided that it would be clearer to republish the corrected version of the letter in its entirety, with a footnote explaining how the errors arose. We apologise for the inaccuracies.

\section{More use should be made of patient oriented quality of life measures}

EDITOR-The New Zealand priority criteria project is worthy of wide debate, and Britain has much to learn from it. ${ }^{12}$ Unlike the approach taken in Oregon, the project recognises that benefits from treatment depend on the selection of patients and the threshold for intervention, which is important in maximising the health gain from healthcare resources. The New Zealand approach also provides a mechanism for addressing equity based on need rather than on service measures such as waiting times and levels of activity.

The criteria used in the project are a mix of symptoms, clinical signs, impairments, disabilities, and handicaps. However, the symptoms and clinical signs (which are impairments themselves) account for most of the available 100 points, while handicap as represented by the criterion "ability to work, care for dependants, or live independently" can score only $10-16$ points maximum. This is explained by the fact that "a certain degree of misgiving was usually noted about incorporating these social factors" during the professional advisory groups' discussions.

This weighting can be criticised because the most important criterion for treatment is surely the impact of a condition on a person's lifestyle rather than the simple presence of a symptom, clinical sign, impairment, or disability. A recent survey of ophthalmologists found that most regarded handicap as being more important than visual acuity when considering whether to offer cataract extractions ${ }^{3}$ - for example, a visual acuity that would prevent driving has a much greater impact on someone whose work entails driving than on non-drivers. The imbalance in the New Zealand weightings might be explained by the fact that there are already well known assessment procedures with severity gradings for symptoms and signs. This adds additional weight to the argument that further development and greater use of handicap or patient oriented quality of life measures are urgently needed in effectiveness and cost effectiveness studies.

Finally, we wish to make a more specific point. Ocular comorbidity, for which treatment is less successful, is usually regarded as a relative contraindication to cataract surgery and should not therefore contribute positively to the overall score.

Alan Mordue Consultant in public health medicine Borders Health Board, Melrose, Roxburghshire TD6 9DB

David W Parkin Senior lecturer in health economics Department of Epidemiology and Public Health, University of Newcastle upon Tyne, Newcastle upon Tyne NE2 4HH

1 Hadorn DC, Holmes AC. The New Zealand priority criteria project. Part 1.Overview. BMJ 1997;314:131-4.

2 Hadorn DC, Holmes AC. The New Zealand priority criteria project. Part 2 . Coronary artery bypass graft surgery. BMJ 1997;314:135-8.

3 Mordue A, Parkin DW, Baxter C, Fawcett G, Stewart M. Thresholds for treatment in cataract surgery.J Public Health Med 1994;16:393-8.

**We suspect that many readers will not know-as we didn't-that the terms "impairment," "disability," and "handicap" have specific meanings, defined by the World Health Organisation. Impairment is defined as "any loss or abnormality of psychological, physiological, or anatomical structure or function"; disability as "any restriction or lack of ability (resulting from an impairment) to perform an activity in the manner or within the range considered normal for a human being"; and handicap as "a disadvantage for a given individual, resulting from an impairment or disability, that limits or prevents the fulfilment of a role (depending on age, sex, and social and cultural factors) for that individual" (defined in 1980). Not realising these definitions, we had adopted a style that took note of the views of patients as promoted by organisations such as RADAR (the Royal Association for Disability and Rehabilitation) and Disability Alliance. These organisations do not use the term handicap because patients believe that it is stigmatising, and our style was also not to use the term. Dr Mordue and Dr Parkin used the terms correctly according to the WHO's definitions, and our editing changed the meaning of their letter. We will change our house style to conform with the definitions in future--EDITOR 